\title{
Multilingual Discourse in News Broadcasting in Pakistani Urdu Channel: A Case Study
}

\author{
Sania Kokab \\ Department of Sciences \& Humanities, National University of Computer and Emerging Sciences Lahore, \\ Pakistan
}

\begin{abstract}
Code-mixing is a common phenomenon in the modern multilingual and bilingual society and it occurs in media as such as it does in other domains of life. This research targeted to find out the scope of code-mixing practicing in Urdu news of a private news channel in Pakistan, and to catch out the equivalent words in Urdu language if there are. Qualitative approach has been applied using the method of Case study. The population consisted of Urdu news aired on the private News channel ARY by using Convenient and Purposive sampling techniques. Forty online audio-video bits and pieces on YouTube which were broadcasted on ARY News channel were recorded for the analysis as a sample. The purpose of this study is to investigate the nature of code switching between English and Urdu languages in light of Myers-Scotton's (1993) Markedness Model .The tabulated data showed that the phenomenon of code-mixing is commonly practiced although having their equivalents in Urdu language. It reflected the general behaviour prevailing in the society about code mixing. The records assisted in finding out if code-mixing is dominant in Urdu news in particular channel and to what extent. Moreover, these recordings also helped to interpret, find substitute and word class of the English word inserted in the Urdu news.
\end{abstract}

Keywords: Case study, Code-mixing, Private Pakistani channel, Urdu news, English Language

DOI: $10.7176 / \mathrm{JLLL} / 72-05$

Publication date:October $31^{\text {st }} 2020$

\section{Introduction}

Urdu is Pakistan's national language and English is official language, besides Urdu various regional languages are spoken, giving it a multilingual status. Undistinguishable this English enjoys a supreme status in the society as an official language. Due to this supremacy of English Language, domination of western culture, negligence of the government in constructing a language policy, the attitude and response of the society towards English Language has initiated the phenomenon of code-mixing in daily communication. Media (electronic and print media) no doubt has played an effective role in the development of communication but at the same time has amplified the phenomenon of code-mixing as being noticed in various researches made in the field (Mushtaq \& Zahra, 2012;Rasul, 2006). It is also giving rise to a hybrid language (Khalid. A, 2011). In a multilingual society, though, the process is inevitable but alarming and has given rise to issues and questions. It is necessary to check and notify against it as it is swiftly changing Urdu language.

Origin of Code-Mixing in Urdu Language:

Urdu language has its roots or origin in Turkish, Arabic and Persian and Sanskrit (Mushtaq \& Zahra, 2012).The time when Sir Syed Ahmed Khan thought of educating people through literature, he insisted on simplifying Urdu Language. In his opinion simple language effects the masses at a greater degree. He not only stressed to use Urdu Literature to educate and reform Muslims of the subcontinent but also paved the way for English Language. In start there was some opposition raised by the society but deliberately and gradually not only "Urdu Assan Tehreek" was fruitful in changing traditional Urdu but English Language was also acknowledged by the society so greatly that it pierced its deep roots into art, literature and music of the Subcontinent. The impact was so prevailing that even after Independence no one could free Pakistan from this aspect.

It can be concluded from the history that Urdu Language has endured many modifications since 1857 . The initial stage of Urdu language was laden with Persian vocabulary. From 1857 to 1947 it became simpler and the Persian impact was reduced to smaller degree. Later after independence, Urdu Language spoken in India was dissimilar from the form spoken in Pakistan. Since 1947, Urdu has been influenced by English Language.

Many words of English Language are well-known and used by people who have never studied the language. Words like plate, glass, television, dressing table, sorry, thank you are commonly used in routine communication having no any awareness of code-mixing.

Role of Urdu Electronic Media in Code-Mixing

Media being an entertainment and recreational platform, also has become a dynamic activity and means of communication in the current society. Specially, now a days the news channels have clutched the attention of people because of the political and economic situation of the country. To gain the "rating scale" all channels are running active in different areas in order to make the news more attention-grabbing and motivating. In short, all strategies are used to gratify the onlookers. On the base of the ground reality that society, language and media are knotted in a close relationship (Rasul, 2006),it is assumed that media is playing a two dimensional role i.e. on one 
hand it reflects the behavior of the society and on the other hand effects and shapes the attitude of the society. As English Language is considered as a language of educated and elite class in Pakistan, therefore mixing of English code in Urdu has become a common social activity. This socio-cultural or technically spoken, socio-linguistic phenomenon is mirrored on media in turn influencing the society.

\subsection{Purpose}

The research is aimed to explore the phenomenon of multilingualism being practiced in Pakistani News Channel. And how people are being indulged in this occurrence specially our illiterate people. And as a response they too adopt this occurrence in their daily routine unconsciously and consciously.

1.1.1 Implications:

The phenomenon of code-mixing is frequently practiced in our society. Although, most of the words have their equivalence in Urdu language but they are not a part of people's active vocabulary and are not usually used in everyday conversations. It reveals the common behavior prevalent in the society that those words are used which are easily available and can facilitate easy and fluent conversation, no matter if they are used by performing codemixing.

This research will help in bringing awareness to news writers and concerned persons about their own practice of code-mixing, so that they remain conscious of the fact that English words do have their equivalents in Urdu language and should be used instead. Moreover, there is a need of making a language policy for the news as they are formal and viewed all over the world.

\subsubsection{Objectives}

The phenomenon of multilingualism is of immense importance in a country like Pakistan where many languages are spoken and occurrence of code mixing is very common in Urdu News Channels.

- $\quad$ It will help in understanding the sociolinguistic culture in the country.

- It is significant as it aims to point out the fact that media has no fixed language policy. The reporters are using English language on their own convenience and primacy.

1.1.3. Research Questions

The study is based on finding answers to the following research questions.

1.4.1.Is code-mixing/switching prevalent in Urdu News bulletin broadcasted on the Channel under study? If so, to what extent?

1.4. 2. What type of code-mixing/switching is used in the News and at what level?

1.4. 3. Is Urdu language sufficient enough to give equivalent of the Inserted English language words?

\section{Literature Review}

The phenomenon of code-mixing is widespread in a multilingual community. This phenomenon has been experienced in many arenas like food discourse, newspapers, television, magazines, radio broadcasts, internet etc. A study of mixing English into Chinese internet language by Bi (2011) indicates that code mixing has become a tendency in "Chinese internet discourse." The mixing of words in Chinese code is not due to or reason of any cultural invasion, rather they are used only to perform linguistic functions. It has also been concluded that "English has become inevitable trend." Much consideration has become a requisite to retain the balance of code-mixing to eliminate misperception and cultural interference.

Muysken (2011) stated that Code-mixing is a procedure in which lexical items and grammatical features of two or more languages occurs in the same stretch of speech or sentence. The aim of this research was to study code mixing of English lexical items in Chinese entertainment news. The researcher determined that the use of abbreviation like 'CD', 'DVD', 'SMS', 'VIP' were added to make news slight and easy to understand. Moreover, some adjectives like hot, cool, high etc. were also added to yield stylish impact and to give a modern touch to the Chinese entertainment news. While doubling of words like 'cute cute', 'high high' is a characteristic of Chinese language, it is not certified in English grammar.

Furthermore some reasons and functions of code mixing have been sightseen by Kanthimathi (1999) in India. This study was directed on college students conducting a questionnaire. It was exposed that level of code mixing depends on different factors such as (i) Quantity of exposure to English (ii) Medium of instruction in school (iii) The rate of language used in several spheres, context and topic under discussion. The outcome of the study is revealed in the succeeding statement: "The world is richer then it is possible to express in any single language" (Prigogone as cited in Kanthimati, 1999).

Likhitphongsathorn and Sappapan (n.d.) piloted a study to know the types of English used in song writing. It was perceived that even music could not release code mixing and code switching. Benthhila and Davies (as cited in Teeratorn \& Pattama, n.d.)Observed that these phenomena are used to produce "rhetorical and aesthetic effect" on listeners. According to Li (2000), people commonly express in English owing to its 'preciseness' and that it involves minus effort. Hawkins (2004) and some others have the view that using English has the ability to 'express the most with the least'. Another study was examined on code-mixing of Thai entertainment programme by 
Kannaovakun and Gunther (2003). Data was a recorded popular entertainment programme. The result presented seven types of code mixing that were used in the programme, they were" mixing the two codes that is Thai and English language, transliteration, clipping, abbreviation, hybridization, using English names and others."

Code-mixing in Thai daily newspapers was studied by Charak. The study aimed to identify linguistic unit mixed in Thai language and to analyse the parts of speech code mixed in the daily newspapers. The researcher categorized the words initiated from code mixing. The frequency was also observed, highest in sports news which was $41 \%$ and the low frequency occurred in economic news which was $10 \%$. One more aspect was explored that code mixing at lexical level is more than at phrasal level. Study of code mixing on internet forum was also studied by Tsang (2006) to explore code mixing of Chinese and English. Data was collected in a real life situation. It was noted that five kinds of linguistic features subsists in computer mediated communications (CMCs). It offers an indication that internet forum communication is a hybrid of writing and speech. He also settled the view that these linguistic features are a product of speaker-writers aspiration to communicate meritoriously and efficiently.

Al-Mulhim (n.d.) also conducted a case-study research to examine the impact of media on code mixing amongst younger generation in Saudi Arabia. The sample contained on young females who were prepared to watch a well-known television programme "Scoop." The goal was to detect how language used in the specific programme stimulated the ladies to use same words in their natural language. The result of this research sustained the hypothesis that media had a great power on the language of young generation of Saudi Arabia.

Furthermore, Shogren, J. B. (2011), analysed code switching and code mixing amongst bilingual children. The study proposed to explore the pattern of code switching and code mixing of two 5 year old children. It was concluded that the boy who had been a bilingual in regular background was prone to code switching, while the girl who has learnt second language consecutively assemblies the two codes in her conversational communication. It leaks the construction or relation between linguistic behaviour and manner of exposure to a language.

A brief review on literature already produced and published on code-mixing between two languages have been presented above. Now, let us have a look at the researchers conducted study on Urdu English code-mixing. In this strain, Mushtaq and Zahra (2012) have analysed code mixing in television commercials. The researchers targeted at analysing scope and effect of code mixing in advertisements publicized on different channels in Pakistan. 3 Pakistani channels that are Geo TV, ARY Digital Network and Hum TV were used for data collection. A questionnaire was circulated to know the opinions and effect of code mixing on the watchers of TV commercials. The research concluded that code mixing subsists to a greater extent in TV commercials and in leaving a forceful and strong impact on the onlookers by serving the purpose of effective communication.

Likewise, Asghar (2012) directed a research and having the view that code-mixing results in hybridization, where two or more languages are repeatedly mixed, it results in a new hybrid variation of language. Though, this new variation shares to some point merits of both languages but it has its own distinctive and self-governing grammar and vocabulary which is incomparable to any of the mixed languages. Asghar supports his assumption by presenting some instances such as "leaderan, machinain, classon, quomi assembly, hakomati memberan..." He also perceived that some speakers are habitual of recapping English equivalents of Urdu words both to show their knowledge and command on English Language and to prompt their status consciousness. Furthermore, Talaat (2002), in her study titled "The Form and Functions of English in Pakistan" collected data from English newspaper and magazines published in Pakistan. The nominated text were analysed by comparing "standard British English" with Urdu sentence structure. It was perceived that Urdu structure critically influenced English Language giving increase to Pakistani English. She also observed structural variance in language and resolved that it is due to codemixing and literal translation.

\section{Research Methodology}

Myers-Scotton's Markedness Model (1993) is applied to analyze the data and to investigate the phenomenon of code mixing/switching in Pakistani Urdu News Channel under study. The model proposed that speakers are expected to select a suitable linguistic code based on the situation in which speakers find themselves. The particular research has monitored using qualitative approach due to the descriptive nature of the particular topic. Due to shortage of time a Case study research was chosen so that the phenomenon can be well understood and analysed within the limitations of a single unit.

\subsection{Theoretical Underpinning}

The Markedness model of code switching, which is accronymised MM, is primarily based on the two critical assumptions. According to Wei (2007), the first assumption is 'negotiation principle'. Myers-Scotton (1993a, $1993 b)$, states that the "negotiation principle" publications interlocutors to pick out the best form for the speakers which correlates with the proper use of obligation (RO) set that they intend to engage in the course of their conversations. The second assumption is the rationale of all code selections (Myers-Scotton, 1993a). For this selection, four maxims were established for instances(1) code switching as 'unmarked choice maxim', (2) code switching as the 'unmarked-choice maxim', (3) code switching the 'marked-choice maxim, and code switching as 
the 'exploratory preference maxim (Myers-Scotton, 1993a, p. 113). Every maxim determines a speaker's linguistic behaviour toward the RO set.

The aim of the present study is to identify Code switching and code-mixing in selected News aired on Private Pakistani Channel. Myers-Scotton (1993) explains Code-switching as the interchanges of linguistic varieties within the same conversation. This description is accepted by this study. The study is qualitative in nature and it involved a comprehensiveand detailed description of code-switching containing examples of code-switching.

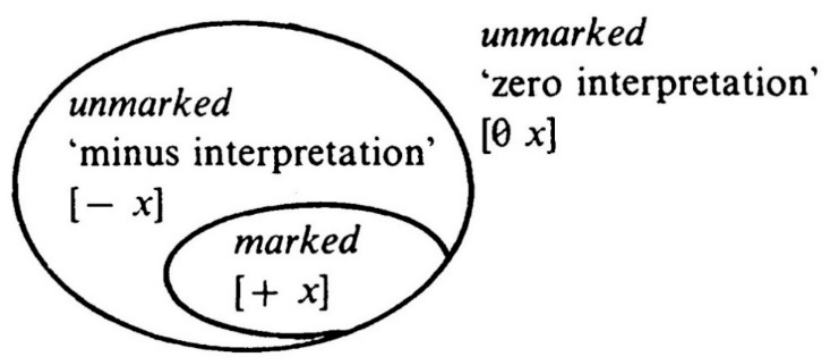

Figure 1. Marked and unmarked choice

This study only revealed the aspect of 'marked' code-choice maxim of the Markedness Model. The 'marked' choice maxim is a negotiation against the 'unmarked' (expected) choice and directs a speaker to call up for another Rights and Obligation (RO) set in the place of the expected choice. Marked choice is adopted due to many motives like for aesthetic effects, direct quotations, structural weakening and to show ethnic identity and group solidarity. Code-switching serve the following functions as well;ease of communication, to fill a lexical gap, for clarification, to create humour, for group identity, to soften or strengthen command or request, for societal factors such as euphemism and for economy.

\section{Data collection}

The news media or news industry are forms of mass media that focus on delivering news to the general public or a target public. These include broadcast news (radio and television) other than print media (newspapers, newsmagazines). News cover many types of news like politics, weather, sports, entertainment, and dynamic events, this regular media shape the prevailing cultural, social and political image of society. Beyond the media networks, independent news foundations have become innovative to report on events which spurt attention or inspire the major stories, so media broadcasting is a credible and popular source of news and analysis. Though social media is considered as more rapid sources of information, but news media is still appreciated for its typicality and sponteintey as compared to the other media. News convey different aspects of important events all the day side by side. They not only represent people's perceptions, events, but also shape their opinions. Therefore, news is considered a powerful tool for rapid and spontaneous information.

\subsection{Population}

Population

The population consisted of Urdu news broadcasted on the Pakistani private News channel ARY.

Sampling

The sampling techniques used for this research were Convenient and Purposive sampling techniques. The sample consisted of 40 audio-video online News (items) records on YouTube which were broadcasted on ARY News channel.

\section{Data Collection Instrument}

The data collection instrument was audio-video recordings of news broadcasted on ARY which were collected via YouTube. The records assisted in finding out if code-mixing is dominant in Urdu news in particular channel and to what extent and to what level. Moreover, these recordings also helped to interpret, find substitute and word class of the English word inserted in the Urdu news.

\subsection{Nature of data}

Data for the study is based on the content of the news aired on ARY News channel and news analysis. Language or linguistic codes used by news readers is studied under the phenomenon of code switching and code mixing. News are a source of information and facts, while analysis of the news provides expert opinions.It is considered that the news with the highest circulation is most widely seen by people. Pakistani news channels paid more attention to their social media presence. In terms of their social media popularity, ARY News is top Pakistani news channels by ranking.ARY News are considered more reliable on social media as well as sharing and liking posts on Facebook. ARY is better in conveying Political News and remained popular when it came to analysis on News. The variety of News from various (aired on) dates and year provided authentic and reliable data for the paper under 
study. I analyzed the broadcast in an attempt to understand the nature and implications of the switching between the two languages (Urdu, English) in the utterances of the news readers in the particular videos.

\subsection{Ethical considerations}

In selecting the data from the news aired on ARY News channel, I tried to be neutral on different aspects. As the context is public and open to everyone, but the analysts afford some privacy through anonymity. As Privacy is a concept that must take into account the expectations and consensus among the participants and the researcher" (Association of Internet Researchers, 2012). So the researcher has difficulties of getting informed consent, the illusion of privacy on Internet etc. The study tried to cover variety of perspectives about particular findings and presented an unbiased view. No other channels are understood as less than ARY and it did not aim to instigate any kind of cultural or social bias against any language. The news analysis is presented without any kind of falsification and biasness.

The data is used only for academic purpose. No argumentation is there regarding news authenticity, speakers' style of conveying news, speakers' identity, and information, perceptions, events conveyed by news readers are set apart and did not aim to spoil the reputation of any of these. The study aimed to analyze the data from news in order to understand how news readers'conceptual orientation influence the choices they make while broadcasting the news.

\section{Data Analysis}

Data collection has been done via the recordings of 40 items News broadcasted on ARY. Data is analysed in tables below with its equivalents of Urdu if they existed.

The equivalent Urdu words were searched out and are listed below against the English words used in the news. Words repeated several times are mentioned only once.

Table 1. English words and their Urdu equivalents (Date of news: 23 March, 2017)

\begin{tabular}{|l|l|}
\hline English words used in Urdu News & Equivalents in Urdu language \\
\hline Bouncers & Sekhi \\
Checking & Janch partal \\
Headlines & Surkhiyan \\
Break & Waqfa \\
Parties & Jamatein \\
Record & Mehfooz kerna \\
Rangers & ------------- \\
Parade & Karkerdagi \\
Performance & ------------ \\
Control center & Muhafiz \\
Guards & Sarak mujrim \\
Street criminals & ----------- \\
bangs & Khana bandi \\
curfew & \\
& \\
\hline
\end{tabular}


Table 2. English words and their Urdu equivalents (Date of news: 1st May, 2016)

\begin{tabular}{|l|l|}
\hline English words used in News & Equivalents in Urdu language \\
\hline Bulletin & Sarkari khabar nama \\
Parliament & Quomi majlis \\
Speakers & Khateeb, muqar'rareen \\
Warrant & Ikhtiyar \\
Announcement & Elaan \\
Clean bold & Saaf mandana \\
BBC & ------------ \\
Chairman & Sadar \\
Career & Tarz e zindagi \\
Anchor person & Nashir kaar \\
Member & Rukan \\
Upset & Preshan \\
Family & Khandan \\
Grand & Aala \\
Ceremony & Taqreeb \\
Conform & Mutabiq/ man'na \\
Finally & Akhir mein/akhir kaar \\
Suspense & Tajasus \\
News up-date & Taza khbrein \\
selection & intikhab \\
& \\
\hline
\end{tabular}

Table 3. English words and their equivalents (date of News: $13^{\text {th }}$ OOctober 2017)

\begin{tabular}{|l|l|}
\hline English words used in News & Equivalents in Urdu language \\
\hline Agenda & Karwai nama \\
Task & Kaam dena \\
Ladies & Khawateen \\
Head quarter & Sadar e daftar \\
Notice & Hukam nama \\
High court & Adalt e aala \\
Security & Hifazat \\
Technology & ----------- \\
Google & ----------- \\
Awards & Inaam \\
Agency & Zahir Numaindagi \\
Sharing & Hisa lena \\
N league & ------------- \\
\hline
\end{tabular}

Table 3: English words and their equivalents (date of News: 13th OOctober 2017)

\begin{tabular}{|l|l|}
\hline Policy & Hikmat e amli \\
Briefing & Ibtadai hadayaat \\
Captain & Captain,sarbhra \\
Election & Intakhabaat \\
Unfortunately & Badqismati se \\
Indirect & Bilwasta \\
Case & Mua'mla \\
operation & Amliya \\
good morning & Subha bakhair \\
public & Awam \\
leader & Qaid \\
committee & majlis \\
\hline
\end{tabular}


Table 4. English words and their Urdu equivalents (Date of news: 30 ${ }^{\text {th }}$ April, 2015)

\begin{tabular}{|c|c|}
\hline Urdu words used in News & equivalents in Urdu language \\
\hline Functional & Faily \\
\hline People's & party Awami jammat \\
\hline Conference & Mashawarat \\
\hline All parties conference & Kul jamati mashawarat \\
\hline Movement & Harkat \\
\hline Dead bodies & Lashyain \\
\hline Team & Jamaat \\
\hline Officer & Auh da dar \\
\hline Join & Dakhil \\
\hline Press conference & -------------- \\
\hline Deadline & muqar ra had \\
\hline Relief & amdaad, aaram \\
\hline Series & silsila war \\
\hline Senchari & |-------------- \\
\hline Remand & zer e tafteesh \\
\hline Media & |------------- \\
\hline International & bayn ul aqwaami \\
\hline
\end{tabular}

Table 5. English words and their Urdu equivalents (Date of news: 02 May, 2015)

\begin{tabular}{|l|l|}
\hline English codes used in News & Equivalents in Urdu language \\
\hline Postmortem & Muaina bad azmarg \\
Europy union & Aman- u -aman \\
Joined & Europy Ittihaad \\
Dialogue & Shamoliat \\
Doctor & Mukalma/Baatcheet \\
Delay & Mualij \\
Polling station & Takhiir \\
Long & Maqam-e-raidehandgi \\
Negative & run \\
Immigration & Taveelmudat \\
Jail & Manfi \\
Code & Tarkeen-e-watan \\
Clearance & Qaidkhana \\
SMS & Khufiy aisharay \\
Manager & Manzoori \\
Professional & ------------ \\
Reaction & Muntazim \\
Arrest & Pesha-war \\
Torture & Rad-e-amal \\
Scanning & Giriftaar \\
\hline & Tashahdud \\
\hline & Amal-e-taqti \\
\hline
\end{tabular}

\section{Findings and Discussion}

The analysis of the recorded news has shown that code mixing is frequently adopted by news readers. The language of news has changed in the past decade. Words like "headlines, breaking news, up-date, break, welcome back......" have their equivalents in Urdu Language and were used in past but with the change in social attitude have been cast-off. 
After a thorough study of the recorded news it was analyzed that code mixing is frequently practiced in the news of the channel under study. Although, most of the words of English language used in the news have their equivalence but are not in everyday use or have become the part of passive lexicon. For example Email (Table 1), Security (Table 2), Bag (Table 5), Curfew (Table3).Usually public is unaware of these equivalent words.

Furthermore, it was analysed that even those English words; whose equivalents are known to public, were also inserted in the News. For example words like Election (Table 2), International (Table 4).

The analysis of the collected data revealed that code mixing is an essential fragment of Urdu news. It was also revealed that intra-sentential code switching occurred mostly in broadcasting news, having the shift in the middle of a sentence mostly or less at start, with no interruptions, hesitations or pauses indicating a shift. Other categories such as intra-word and inter-sentential code-switching were very less. Only surface code mixing occurred in the recorded news code mixing and it occurred at word level frequently and at phrasal level infrequently. It was also perceived that many lexical categories are code mixed, where nouns are at large number and verbs, adjectives and adverbs are less.

The results of the study discovered that Urdu language is rich in vocabulary but there is some lack of vocabulary related to science and technology and Government office register. Its reason is that the research and development in the field of science and technology has been done by the west therefore, its terminology or vocabulary is in English language, and English as an official language of Pakistan rules on all important departments and domains of the country. It is the language of court, forces, government, trade \& commerce and science \& technology. It has become an essential fragment of the society so much so that even politics could not escape from its hold. This caused in mixing English code in all circles of life in our country. Analysis of the data demonstrated that words related to official departments were used in English, though Urdu language has substitute of these words. For example:

- Words related to government Chairman, high court, Supreme Court, Chief Justice, meeting, assembly, notification and many more

- Words related to court Warrant, law and order, magistrate, jail, Supreme Court.

- Words related to politics Abbreviations of all political party names such as PPP, MQM, PTI, MNA etc.

- Words related to science and technology Email, website, mobile phone, telephone, revolver, rifle etc.

- Words related to forces Air force, army chief, army, rangers

- Acronyms and abbreviations CNG, ICU, CCTV, ASF, ISBR

- Words related to trade and commerce Sales tax, tax.

Besides this, some words are also commonly used in English language instead of Urdu language like name of colours and some objects for example white, navy blue, red, coat, jacket, trousers etc. Moreover, some words for example ballot paper, polling station, returning officer, presiding officer, mobile market, megawatt, and load shedding, have no alternate in Urdu language. The study also showing that some words have their alternates but have become part of Urdu language, for example doctor, hospital, ICU. The dominancy of language is observed in the names of the places also, for example Defence Phase 1 and Kurram Agency.

\section{Conclusion}

The analysis of the recorded news has exposed that frequently there is use of code mixing and often unconsciously implemented in news writing as well as by news casters when reporting live and spontaneously. From the past decade language of news from use of pure Urdu has altered to a great extent. Words like "headlines, breaking news, up-date, break, welcome back, etc." are habitually used in Urdu news, ignoring the fact that they have their equivalents in Urdu language. Equally, these equivalents have been castoff in view of the changing attitude of the society regarding Urdu and English language.

It would not be suffice to state that a good amount of English words has become an integral part in our daily conversation. What is more to evaluate is that there are certain classifications or groups of words that generally occur more than others. We can group these words in several ways: Firstly, the words known as 'loan and borrowed words' like Traffic, Driver, Doctor, and Officer which have entered in Urdu language from English and used by all classes of people in daily conversation hence imitated in the news. Secondly, the abbreviations and acronym like CCTV, CNG, SMS, ASF, ISPR and CT scan were also broadly used in Urdu news because their full-forms are technical and more difficult to pronounce and comprehend. Thirdly, names of places, such as police station, airport, hospital, hotel, assembly and jail were also commonly used in the news under observation and in daily life too.

Fourthly, names of professions and designations like doctor magistrate, chief justice, governor, security guard, election commissioner and director general were also noted in English. In addition, words concerning to certain specific organizations and departments for instance turbine, trip, feeder, grid station, power station, polling station, ballot paper, polling officer, vote, load shedding were also found in English language. Along with this different forces names were also mentioned in English language such as army, air force, British air force, army chief. 
Words for scientific technology, being developed by western countries, like e-mail, mobile phone, websites, SMS, were also eminent in English language. Likewise, names of weapons like rifle, revolver, SMG, grenade, bomb etc. Again, word concerning to trade and commerce like tax and sales tax were also noticed.

Hence it is concluded that news writers and casters, on the particular channel under discussion, mix English code in Urdu news very habitually and subconsciously having the prime intention to convey their message to the viewers in the best conceivable way. Secondly, there are some other motives behind this code-mixing. The most important is the utilitarian approach of the society that is people hesitate in making an effort to search out the equal word in Urdu language. Additionally, some of the English words used in the news do not have their alternatives in Urdu language. While some words have their substitutes in Urdu but they are either in users passive vocabulary or sometimes they are completely unfamiliar to them. As a result, they utilize any word at hand, be it a word from English language to achieve their communication. In conclusion, code switching/mixing is a phenomenon that is inevitable in bilingual communities and understood as a creative process. However, it is condemned as incompetence in language too. But it is natural and innovative process and can be turned to a purposeful and useful notion.

\section{Recommendations and Suggestions:}

First of all there is a need of a language policy to be made according to our current situation and needs which should be strictly followed. This could be prove as aid in future research and further study in the domain of multilingualism.In the light of above study it is recommended for researchers to proceed this research using more cohesive techniques to measure data as this is qualitative study.

\section{References}

Al-Mulhim, N. I. (n.d.) The Influence of Media on Encouraging Code Mixing in Saudi Arabia.http://www.academia.edu/1016123/The_Influence_of_Media_on_Encouraging Code Mixing in Saudi Arabia

Asghar, S. (2012). Code-mixing and Language Hybridization. Pakistan: Govt. Razvia Islamia College

Bi, N. Z. (2011). An Investigation into English Mixing in Chinese Internet Language. World Journal of English Language, 1(2).

China Education and Research Network (CERN) (2001). Top 100Chinese Website. Retrieved October 01, 2009, from http://www.edu.cn/20010101/22272.shtml

Hamers. J. F. \& Blanc, M. H. A. (1989). Bilinguality and bilingualism. Cambridge: Cambridge University Press. Hawkins , J. A. (2004). Efficiency and Complexity in grammar. London: Person Education.

Herawati, N. (2013). Code Mixing Used In Women Magazine: A Sociolinguistic Study. Retrieved from http://unrika.ac.id/index.php/code-mixing-used-in-women-magazine-asociolinguistic-study

https://propakistani.pk/2017/07/17/popular-tv-channels-topics-pakistani-social-media/

Kantimathi, K. (1999). Mixing Mother Tongue and English: Exploring the Reasons and Functions of Code-mixing. The Second Biennial International Conference on Teaching and Learning of English in Asia: Exploring New Frontiers (TELiA2), 14-16 June 2007, Holiday Villa Beach \& Spa Resort, Langkawi.

Khalid, A. (2011, June 21). Urdu v/s English: Are we ashamed of our language? [The Express Tribune Web log post]. Retrieved from: http://blogs.tribune.com.pk/story/6545/urdu-vs-english-are-we-ashamed-ofourlanguage/

Li, D. C. S. (2000). Cantonese-English code-switching research in Hong Kong: aY2K review. World Englishes, 19(3), 305-322. http://dx.doi.org/10.1111/1467-971X.00181

Likhitphongsathorn, T. \& Sappapan, P. (n.d.). Study of English Code-mixing and Codeswitching in Thai Pop Songs. Retrieved from www.fllt2013.org/private folder/Proceeding/494.pdf

Mushtaq, H. \& Zahra, T. (2012).An Analysis of Code-Mixing in Television Commercials. Language in India, $12(11)$.

Myers-Scotton, Carol. (1998) Codes and Consequences: Choosing Linguistic Varieties. Oxford University Press US

Myers-Scotton, Carol. (1993) "Common and Uncommon Ground: Social and Structural Factors in Codeswitching”. Language in Society, Vol. 22, No. 4 (Dec., 1993), pp. 475-503. Cambridge University Press

Rasul, S. (2006).Language Hybridization in Pakistan as Socio-cultural Phenomenon: An Analysisof Code-mixed Linguistic Patterns. Retrieved from http://prr.hec.gov.pk/thesis/2426.pdf

Shen, C. (2010). A Study of Chinese-English Code-switching in Chinese Sports News Reports. Cross-Cultural Communication, 6(4), 165-175.

Shogren, J. B. (2011). Analysis of Code-switching and Code-mixing among Bilingual children.

Talaat, Ms. Mubina. (2002). The Form And Functions Of English In Pakistan. PhD thesis, Bahauddin Zakariya University, Multan.

Teeratorn \& Pattama.(n.d.).Study of English Code Mixing and Code Switching in Thai Pop Songs. Retrieved from 
http://www.fllt2013.org/private folder/Proceeding/494.pdf

Tsang, C. M. G. (2006). The Processing of Code-mixing of Chinese and English on Internet Forum: A Hong Kong Case Study. Hong Kong: The Chinese University of Hong Kong.

\section{Appendix:}

https://www.youtube.com/results?search_query=ARY++headlines + of $+02+$ May $\% 2 \mathrm{C}+2013$

http://videos.arynews.tv/headlines-2000-thursday-30-april-2015/

https://www.google.com.pk/?gws_rd=cr,ssl\&ei=Vu78WN6ZEiE6ASHiJDAAg\#q=ary+news+of+23+april+2017 +on+youtube

https://www.youtube.com/watch?v=c58PA-iJp_o https://www.youtube.com/watch?v=7LtlxWCMpuU http://videos.arynews.tv/headlines-2100-13th-october-2017/

http://videos.arynews.tv/headlines-1500-thursday-30-april-2015/ 